\begin{tabular}{cc|c}
\hline Tar. Bil. Der. & Journal of Agricultural Sciences \\
& $\begin{array}{c}\text { Dergi web sayfası: } \\
\text { www.agri.ankara.edu.tr/dergi }\end{array}$ & Journal homepage: \\
& www.agri.ankara.edu.tr/journal
\end{tabular}

\title{
Mısır Yetiştiriciliğinde Erken Toprak İşleme ve Glyphosate'nin Çıkış Öncesi ve Çıkış Sonrası Yabancı Ot Mücadele Yöntemleri ile Birlikte Kullanılabilirliğinin Araştırılması
}

\author{
Doğan ISIK ${ }^{\mathrm{a}}$, Mahmut DOK ${ }^{\mathrm{b}}$, Emine KAYA ALTOP ${ }^{\mathrm{c}}$, Hüsrev MENNAN \\ a Erciyes Üniversitesi, Ziraat Fakültesi, Bitki Koruma Bölümü, Kayseri, TÜRKIYE

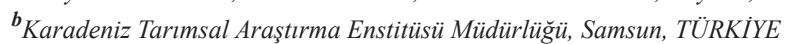 \\ ${ }^{c}$ Ondokuz Mayls Üniversitesi, Ziraat Fakültesi, Bitki Koruma Bölümü, Samsun, TÜRKiYE
}

\section{ESER BILGISII}

Araştırma Makalesi

DOI: 10.1501/Tarimbil_0000001360

Sorumlu Yazar: Doğan ISIK, E-posta: dogani@erciyes.edu.tr, Tel: +90 (352) 4376209

Geliş Tarihi: 15 Temmuz 2014, Düzeltmelerin Gelişi: 31 Ekim 2014, Kabul: 12 Kasım 2014

\begin{abstract}
ÖZET
Bu çalışma dane mısır yetiştiriciliğinde yabancı otlarla mücadele etkinliğini artırmak amacıyla 2011-2012 yıllarında Karadeniz Tarımsal Araştırma Enstitüsünde yürütülmüştür. Çalışmada yabancı ot rekabetini azaltmak için erken toprak işleme ve bu alanlarda ekim öncesi ve çıkış öncesi glyphosate'nin kullanılabilirliği diğer mücadele yöntemleri ile kombine edilerek araştırılmıştır. Deneme tesadüf bloklarında bölünmüş parseller deneme deseninde yürütülmüş ana parsellere glyphosate'nin uygulama zamanları ve mekanik mücadele yerleştirilmiş, alt parsellere ise çıkış öncesi ve sonrası herbisit uygulamaları ve çapa uygulaması yerleştirilmiştir. Çalışma sonucunda mısır tarımında ekim öncesi ve çıkış öncesi glyphosate uygulamalarının yapılabileceği belirlenmiştir. Çalışmada en düşük yabancı ot biyoması ise ekim öncesi glyphosate ve çıkış sonrası selektif herbisitlerin birlikte kullanıldığ 1 parsellerden elde edilmiştir.
\end{abstract}

Anahtar Kelimeler: Mısır; Yabancı ot; Glyphosate; Herbisit; Çapa

\section{Applicability of Early Tillage and Glyphosate Together with Pre and Post Emergence Weed Control in Corn Production}

\section{ARTICLE INFO}

Research Article

Corresponding Author: Doğan ISIK, E-mail: dogani@erciyes.edu.tr, Tel: +90 (352) 4376209

Received: 15 July 2014, Received in Revised Form: 31 October 2014, Accepted: 12 November 2014

\section{ABSTRACT}

This study was carried out to improve the effectiveness of weed control in corn production during $2011-2012$ years at the Black Sea Agricultural Research Institute. To reduce weed competition, the applicability of early tillage and pre-sowing and pre-emergence treatment of glyphosate in combination with other methods of weed controls was investigated in this study. Experiments were conducted in randomized blocks in a split plots experimental design with four replications. 
Glyphosate treatment periods and mechanical control were placed into main plots and pre + post emergence herbicide and hoeing treatments were placed into sub-plots. As a result it has been concluded that pre sowing and pre emergence application of glyphosate could be applied in corn production. The lowest weed biomass was obtained from the preemergence glyphosate applied plots and post-emergence selective herbicide applied plots.

Keywords: Corn; Weed; Glyphosate; Herbicide; Hoeing

(C) Ankara Üniversitesi Ziraat Fakültesi

\section{Giris}

Dünya tahıl üretiminde buğdaydan sonra ikinci sırada yer alan misır gerek insan beslenmesinde gerekse hayvan yetiştiriciliğinde başlıca karbonhidrat kaynağ1 olarak yararlanılan önemli bir üründür. Özellikle biyoetanol üretiminde kullanımının artması, mısır fiyatlarında ve üretiminde artışlara neden olmuştur. Dünya mısır üretimi 2012 yılında 875.1 milyon ton olup, 2020 yılında 1 milyar tonun üzerinde üretime ulaşması beklenmektedir (Özata \& Kapar 2013).

Ülkemizde mısır, tahıl üretimi içinde ekiliş alanında buğdaydan sonra ikinci, verimde ise ilk sırayı almakta olup, ekiliş alanı son on yılda $\% 16.5$ (652.784 ha), üretim ise \% 210 artış (5.900.000 ton) sağlamıştır. Yüksek verimli hibritlerin ekilmesi tane verim ortalamasin $500 \mathrm{~kg}$ $\mathrm{da}^{-1}$ 'dan $904 \mathrm{~kg} \mathrm{da}^{-1}$ 'a kadar artırmıştır (Özata \& Kapar 2013). Karadeniz Bölgesinde misır üretimi ekonomik anlamda en yoğun olarak Çarşamba ve Bafra ovalarının oluşturduğu Samsun ilinden sağlanmaktadır. Samsun ilinde 2012 yılı verilerine göre yaklaşık 186.863 da alanda tane mısır üretimi gerçekleştirilmiş, dekardan $504 \mathrm{~kg}$ verim alınmıştır (TÜíK 2013).

Yabanc1 otlar diğer ülkelerde olduğu gibi Türkiye'de de mısır üretimini sınırlayan faktörlerin başında gelmektedir. Mısır üretiminde yabancı otların neden olduğu ürün kaybı \% 37 civarındadır (Oerke \& Dehne 2004). Yabanc1 otların neden olduğu zararlardan en önemlisi, kültür bitkisi ile su, 1şık, mineral besin maddeleri ve yer bakımından rekabetleridir. Özellikle erken dönemlerde zarar daha fazladır. Zira yabancı otlar kısa zamanda gelişmekte ve verimi etkilemektedir (Özer 1993).
Türkiye'de mısır tarımında yabancı ot mücadelesi önemli maliyet kaynaklarından birisi olup, kritik periyot döneminde ekonomik yabanc1 ot kontrolü için gerekli önlemler alınmalıdır. Samsun'da yapılan kritik periyot çalışmasında, yabancı otlardan kaynaklanan ürün kaybını azaltmak için mısırın çıkıştan sonraki ilk 6 hafta yabancı otsuz tutulması gerekmektedir (Işık et al 2006). Mısırda yabancı ot kontrolü başlıca mekanik ve kimyasal yöntemlerle yapılmakla birlikte; üretim alanındaki ve maliyetlerdeki artışlarla birlikte herbisit kullanımı da artış göstermektedir (Kır \& Doğan 2009).

Mısırda ekim öncesi yabancı ot kontrolü için toprak herbisitlerinin yanı sıra toprak işleme yaygın uygulamalardandır. Bu uygulamalar; yüksek maliyet ve toprak işlemeden kaynaklanan toprak erozyonu; herbisitlerin toprakta tutunması ve yoğun ilaçlamalar sonucunda dayanıklılık oluşumu gibi çevresel etkenler nedeni ile etkisiz kalmakta, çoğu durumda alınan bu koruyucu önlemlere rağmen kritik periyodun başlangıcında yabancı ot yoğunluğu yüksek olabilmektedir. Bu nedenle ekim öncesi ya da çıkış öncesi yabancı ot problemini azaltmak için yeni yaklaşımlara ihtiyaç duyulmaktadır.

Son çalışmalarda yabancı ot popülasyonunun azaltılması ve ürünü erken gelişme döneminde yabancı ot rekabetinden korumak amaçlanmaktadır (Doğan et al 2009). Bu sistemin temel amacı erken toprak işleme ile (tohum ekiminden haftalar önce) ekim öncesi yabancı ot tohumlarının çimlenmesini teşvik etmek, böylece çimlenen yabancı otları ikincil bir toprak işleme ya da geniş spektrumlu herbisitlerle yok etmektir. Tarım alanlarındaki yabancı otların çoğu yüzeye yakın 6 cm'lik toprak profilinden çıkarlar (Cousens \& Moss 1990). Erken tohum yatağı hazırlığı ile üst toprak katmanındaki 
yabancı otların çıkış yapması ve ürün ekiminden hemen önce öldürülmesi sistemin başarısı olarak kabul edilir. Bununla birlikte çimlenme bölgesinden yabancı otların çıkış yapması; yabancı ot türüne, toprak tipine, toprak işlemeye ve toprağın fiziksel özelliklerine göre değişmektedir (Buhler \& Mester 1991; Mohler \& Galford 1997).

$\mathrm{Bu}$ amaçla herbisit olarak daha çok glyphosate kullanılmakta olup, geniş spektrumlu bir herbisit olan glyphosate'nin çevreye olumsuz etkileri çok düşüktür. Toprakta toprak kolloidlerine tutunma oranı yüksek ve kalıcılığı düşük olan glyphosate'nin mısır tarımında mısır çıkışından sonra kullanılması mümkün olmamakla birlikte; ekim öncesi ve çıkış öncesi çimlenmesi teşvik edilmiş yabancı otların mücadelesinde kullanımı mümkündür. Ülkemizde pamukta yapılan bir çalışmada glyphosate'nin ekim öncesi ve çıkış öncesi kullanılabileceği gösterilmiştir (Doğan et al 2009).

$\mathrm{Bu}$ araştırmanın temel amacı geleneksel toprak işlemenin yapıldığı alanlarda kritik periyot döneminde mısırı yabancı otsuz tutmayı sağlayacak uygun bir yöntemin ortaya konulmasıdır. Bununla birlikte erken tohum yatağı hazırlığı yapılarak çıkış yapan yabancı otların mücadelesinde; gerek mekanik yöntemlerin gerekse de glyphosate'nin ekim öncesi kullanılabilirliğinin araştırılmasıdır.

\section{Materyal ve Yöntem}

Mısır yetiştiriciliğinde yabancı otlarla mücadelede etkinliği artırmak amacı ile yapılmış olan bu araştırma 2011-2012 y1llarında Samsun Karadeniz Tarımsal Araştırma Enstitüsü deneme sahasında çakılı olarak yürütmüştür. Deneme sahasının toprak yapisı genellikle alüvyonlu topraklardan oluşmuştur. Mineral bileşimleri heterojen, taban suyu yüksektir. Deneme alanının 0-20 cm derinliğinden alınan toprak örneklerinin analizine göre toprak bünyesi killi tınlı olup pH 7.22'dir. Organik madde oran $1 \% 3.28$, toplam tuz oran $\%$ 0.08 , kireç oran1 \% 0.32 olup $15.1 \mathrm{~kg} \mathrm{da}^{-1} \mathrm{P}_{2} \mathrm{O}_{5}$, $56 \mathrm{~kg} \mathrm{da}^{-1} \mathrm{~K}_{2} \mathrm{O}$ içermektedir. Misır yetiştirme sezonundaki denemenin yürütüldüğü yıllar ve uzun yıllar ortalamasını gösteren aylık ortalama sıcaklık $\left({ }^{\circ} \mathrm{C}\right)$, nispi nem $(\%)$ ve ortalama yağış miktarı $(\mathrm{mm})$, deneme sahasına $5 \mathrm{~km}$ mesafedeki Çarşamba hava alanına ait meteoroloji istasyonundan alınmıştır (Çizelge 1).

Mısır yetiştiriciliğinde ürünün yabancı otsuz tutulması gereken kritik periyot döneminde yabanc1 otlarla mücadelede etkinliği artırmak için yapılan bu araştırmanın ilk yılında 18.05.2011 ve ikinci yılında ise 18.04.2012 tarihinde, tohum ekimi yapılmadan yaklaşı 1 ay önce toprak işleme ve tohum yatağ1 hazırlığı yapılmıştır. $\mathrm{Bu}$ araziye 20 gün boyunca

Çizelge 1- 2011-2012 ve uzun yıllar mısır yetiştirme sezonunda Samsun iline ait bazı meteorolojik veriler Table 1-2011-2012 and long-term meteorological data for the research site

\begin{tabular}{|c|c|c|c|c|c|c|c|c|c|}
\hline \multirow[b]{2}{*}{ Aylar } & \multicolumn{3}{|c|}{ Sicaklık ortalama $\left({ }^{\circ} \mathrm{C}\right)$} & \multicolumn{3}{|c|}{ Nispi nem (\%) } & \multicolumn{3}{|c|}{ Yağış toplamı (mm) } \\
\hline & $\begin{array}{l}\text { Uzun } \\
\text { yillar }\end{array}$ & 2011 & 2012 & $\begin{array}{l}\text { Uzun } \\
\text { yillar }\end{array}$ & 2011 & 2012 & $\begin{array}{l}\text { Uzun } \\
\text { yillar }\end{array}$ & 2011 & 2012 \\
\hline Nisan & $11.1 *$ & 10.0 & 13.3 & 79.5 & 80.0 & 74.4 & 58.3 & 60.6 & 10.4 \\
\hline Mayıs & 15.3 & 15.0 & 17.5 & 80.6 & 76.6 & 82.3 & 50.6 & 66.1 & 34.4 \\
\hline Haziran & 20.0 & 20.6 & 21.9 & 76.3 & 80.7 & 76.4 & 47.9 & 49.6 & 24.4 \\
\hline Temmuz & 23.1 & 24.3 & 24.0 & 73.4 & 80.5 & 77.1 & 31.3 & 26.0 & 96.0 \\
\hline Ağustos & 23.2 & 23.4 & 23.0 & 73.7 & 75.9 & 78.0 & 50.9 & 14.2 & 179.6 \\
\hline Eylül & 19.8 & 19.8 & 20.1 & 74.7 & 77.3 & 80.4 & 87.4 & 39.1 & 113.0 \\
\hline Ekim & 15.9 & 15.8 & 16.2 & 75.8 & 76.7 & 80.5 & 87.4 & 90.5 & 60.5 \\
\hline Ortalama & 18.3 & 18.4 & 19.4 & 76.3 & 78.5 & 78.4 & - & - & - \\
\hline Toplam & - & - & - & - & - & - & 413.8 & 346.1 & 518.3 \\
\hline
\end{tabular}

*, Samsun meteoroloji bölge müdürlüğü kayıtları 
başka işlem yapılmayarak, yabancı otların çoğunlukla çıkış yaptığı üst toprak tabakasındaki $(6-8 \mathrm{~cm})$ dormant olmayan yabancı otların çıkıș yapması beklenmiştir. Daha sonra bu alanda çıkış yapan yabanc1 otlarla, glyphosate isopropylamine tuzu (480 $\mathrm{g} \mathrm{L}^{-1}$ ) (Roundup Star) $600 \mathrm{cc} \mathrm{da}^{-1}$ dozunda (3 değişik zamanda) uygulaması yapılarak ve kültürel yöntemler kullanılarak mücadele edilmiştir.

Bununla birlikte daha önceki çalışmalara göre mısır \% 5'lik verim kaybı dikkate alındığında mısır çıkışından sonraki 5-6 haftalık süre (mısırın 1-6 yapraklı dönemi) olan kritik periyot döneminde (Işık et al 2006) daha sonra çıkış yapan yabancı otlarla en uygun mücadele yönteminin tespiti amaciyla çıkış öncesi ve çıkış sonrası herbisitler, çapa ve bunların kombinasyonu denenmiştir. Çıkış öncesi olarak Acetochlor $\left(840 \mathrm{~g} \mathrm{~L}^{-1}\right)$ etkili maddeli herbisit (Guardian) $200 \mathrm{~g} \mathrm{da}^{-1}$ dozda, çıkış sonrası olarak Foramsulfuron $\left(22.5 \mathrm{~g} \mathrm{~L}^{-1}\right)$ etkili maddeli herbisit (Ekipp) $200 \mathrm{~mL} \mathrm{da}^{-1}$ dozda uygulanmıştır. Herbisitler tavsiye dozunda, ana parsellerde traktörle çekilen tarla pülverizatörü ile alt parsellerde ise portatif şarjlı deneme pülverizatörü ile 3 atmosfer basınçta uygulanmıştır. Çalışmada $110^{\circ}$ açıya ve $0.56 \mathrm{~L} \mathrm{dk}^{-1}$ verdiye sahip yelpaze hüzmeli meme kullanılmıştır.

Denemede Karadeniz Yıldızı mısır çeşidi kullanılmış olup pnömatik mısır ekim mibzeri ile $70 \times 20 \mathrm{~cm}$ aralıklarla ekilmiştir. Denemeler bölünmüş parseller deneme desenine göre 4 tekerrürlü olarak kurulmuş olup parsel boyutları $2.8 \times 5=14 \mathrm{~m}^{2}$ olarak ve toplamda $5 \times 4 \times 4=80$ parselden oluşmuştur ( 5 ana parsel, 4 alt parsel ve 4 tekerrür). Parseller arasında 1 m'lik emniyet şeridi bırakılmıştır. Ana parsellere glyphosate uygulama zamanları a) tohum ekiminden 10 gün önce glyphosate uygulaması, b) tohum ekimiyle aynı gün glyphosate uygulaması, c) tohum ekiminden 5 gün sonra glyphosate uygulamas1, d) rotatiller ile mekanik mücadele ve e) kontrol (Çiftçi uygulaması (ekimden 2-3 gün önce toprak işleme ve tohum yatağı hazırlığı)) yerleştirilmiştir. Alt parsellere ise a) çıkış öncesi +çıkış sonrası herbisit uygulaması, b) çıkış öncesi herbisit + frezeli çapalama, c) çıkış sonrası herbisit + frezeli çapalama ve d) çıkış sonrası 2 çapa (frezeli ve lister çapa) uygulamaları yerleştirilmiştir. Denemedeki uygulamaların yapıldığı tarihler Çizelge 2'de yıllar bazında ayrıntılı olarak verilmiştir. Gübre olarak $20 \mathrm{~kg} \mathrm{da}^{-1}$ azot, $8 \mathrm{~kg} \mathrm{da}^{-1}$ fosfor saf madde olarak uygulanmıştır. Azotlu gübrenin $10 \mathrm{~kg}$ '1 ekimle birlikte, geri kalan 10 kg' 1 da bitkiler $40-50 \mathrm{~cm}$ olduğu zaman uygulanmıştır.

\subsection{Yabancı ot saylm ve değerlendirmeleri}

Glyphosate, ekim öncesi ve çıkış sonrası uygulanan herbisitlerden önce parseldeki yabancı ot türleri ve kaplama oranları $0.25 \quad \mathrm{~m}^{2}$ 'lik çerçeveler kullanılarak hesaplanmıştır. Uygulamaların yabancı otlara etkinliğini saptama amacıyla herbisit

\section{Çizelge 2- Uygulamaların yapıldığı tarihler}

Table 2-Treatment date

\begin{tabular}{lcc}
\hline Uygulama & 2011 & 2012 \\
\hline Toprak işleme & 18.05 .2011 & 18.04 .2012 \\
Ekim & 15.06 .2011 & 31.05 .2012 \\
Tohum ekiminden 10 gün önce glyphosate uygulaması & 05.06 .2011 & 21.05 .2012 \\
Tohum ekimiyle aynı gün glyphosate uygulaması & 15.06 .2011 & 31.05 .2012 \\
Tohum ekiminden 5 gün sonra glyphosate uygulaması & 20.06 .2011 & 04.06 .2012 \\
Rotatiller ile mekanik mücadele & 15.06 .2011 & 30.05 .2012 \\
Çiftçi uygulaması & 10.06 .2011 & 25.05 .2012 \\
Çııı̧ öncesi herbisit uygulaması & 15.06 .2011 & 31.05 .2012 \\
Çıkış sonrası herbisit uygulaması & 13.07 .2011 & 25.06 .2012 \\
1.çapa & 14.07 .2011 & 25.06 .2012 \\
2. çapa & 21.07 .2011 & 04.07 .2012 \\
\hline
\end{tabular}

Tarım Bilimleri Dergisi - Journal of Agricultural Sciences 21 (2015) 596-605 
uygulamalarından 14, 28 ve 56 gün sonra \% etki şeklinde değerlendirmeler yapılmıştır. Ayrıca uygulamaların mısır üzerindeki fitotoksik etkileri de kontrol edilmiştir.

Uygulamalardan sonra her parseldeki $1 \mathrm{~m}^{2}$ alandaki yabancı otlar toprak yüzeyinden hasat edilerek ortalama yabancı ot yaş ve kuru biyomasları saptanmıştır. Kuru biyomasların belirlenmesi amaciyla kese kağıtlarına konan yabancı otlar etüvde $70{ }^{\circ} \mathrm{C}$ 'de 48 saat bekletilerek tartımları yapılmıştır (Doğan et al 2009). Mısır dane verimini hesaplamak amaciyla 4 siralı parsellerin birer sirası kenar tesiri olarak bırakılarak ortadaki 2 sıra hasat edilmiştir. Hasat edilen parsellerde nem ve tane koçan oranı değerleri alınmıştır.

\subsection{Ekonomik analiz}

Uygulamaların maliyetlerinin değerlendirilmesi amaciyla net gelir sistemi kullanılmıştır. Bu amaçla dekara sabit ve değişken masraflar hesaplanarak dekara toplam masraf bulunmuştur. Ana ürün ve yan ürün fiyatları hesaplanarak toplam gelir bulunmuştur. Toplam gelirden toplam masraflar çıkarılarak net gelir hesaplanmıştır.

\subsection{Istatistiki analiz}

Elde edilen verilerin istatistiki analizi için SPSS 20- 2012 (SPSS 2012) programında varyans analizi (ANOVA) yapılmış, önemli olan özelliklerin çoklu karşılaştırılmasında ise LSD testi uygulanmış ve sonuçlar irdelenmiştir.

\section{Bulgular ve Tartışma}

\subsection{Deneme sahasinda bulunan yabancl otlar}

Denemenin yürütüldüğü alanda Xanthium strumarium L. (domuz pitrağı), Abutilon theophrastii Medik. (imam pamuğu), Amaranhus retroflexus L. (horoz ibiği), Polygonum lapathifolium L. (sarmaşık çoban değneği), Convolvulus arvensis L. (tarla sarmaşığı), Echinochloa crus-galli P.B. (darıcan), Datura stroamonium L. (şeytan elması), Chenopodium album L. (sirken), Seteria glauca (L.) P.B (kirpi darı) Rumex crispus L. (kuzu kulağı) yoğunluk açısından en çok bulunan yabancı ot türleri olmuştur.

\subsection{Uygulamaların yabancı ot biyomas ăgırlı̆̆ına etkisi}

Erken toprak işlemesi ile yabancı otların çıkışlarının teşvik edilmesi ve çıkış yapan yabancı otlara karşı total herbisit glyphosate'nin kullanım zamanının belirlenmesi ile misırın kritik periyot döneminde yabancı otsuz tutmayı sağlayacak en uygun yöntemin belirlenmesi amaciyla yürütülen bu çalışmada; uygulamaların yabancı otların biyomasları üzerine etkileri Çizelge 3 'te verilmiştir. Uygulamaların yabancı otlar üzerine etkileri hem yıl bazında hem ana parsellerde hem de alt parsellerde istatistiki açıdan çok önemli olduğu tespit edilmiştir (Çizelge 3). Yıllar bazında farklılık istatistiki olarak önemli bulunduğundan yıl birleştirmesi yapılmıştır. Çizelge 3 incelendiğinde ana parsellerde en düşük yabancı ot kuru biyomas ağırlığı kontrolden (çiftçi uygulaması) elde edilirken, mekanik mücadele ile kontrol (çiftçi uygulaması) aynı grupta yer almıştır. Ana parsellerde en yüksek yabancı ot kuru biyomas ağırlığg ise tohum ekiminden 5 gün sonra glyphosate uygulamasından elde edilmiştir. Alt parsellerde ise en düşük yabanc1 ot kuru biyoması çıkış sonrası herbisit uygulanan parsellerden elde edilirken en yüksek yabancı ot kuru biyoması çıkış sonrası iki çapa yapılan parsellerden elde edilmiştir. Bununla birlikte denemedeki yabancı otların kaplama alanları Çizelge 4' te verilmiştir. Yabancı otların kaplama alanları düşük olup, yüksek olanlarda ise bu durum sıra üzerindeki yabancı otlardan kaynaklanmaktadır (Çizelge 4).

Yabanc1 ot yaş biyomas değerlerinin $\left(\mathrm{g} \mathrm{m}^{-2}\right)$ interaksiyon tablosu yıllar bazında ve iki yılın birleştirilmiş analizi Çizelge 5'te gösterilmiştir. En yüksek yabancı ot yaş biyoması 2011 yılında $290.3 \mathrm{~g} \mathrm{~m}^{-2}$ ile ekimle birlikte glyphosate uygulaması yapılan ana parsellere çıkış sonrası 2 çapa (frezeli+lister) uygulanan alt parsellerden elde edilirken 2012 yılında ise $1636.73 \mathrm{~g} \mathrm{~m}^{-2}$ ile ekimden 5 gün sonra glyphosate uygulaması ve çıkış sonrası 2 çapa (frezeli+lister) uygulanan parsellerden elde edilmiştir (Çizelge 5). En düşük yabancı ot yaş 


\section{Çizelge 3- Uygulamaların yabancı ot yaş ve kuru biyomas değerlerine etkileri}

Table 3- The effect of treatments on weed fresh and dry biomasses

\begin{tabular}{|c|c|c|c|c|c|c|c|}
\hline \multirow{2}{*}{\multicolumn{2}{|c|}{$\begin{array}{l}\text { A-Ana parseller- } \\
\text { Glyphosate uygulama zamanlarl }\end{array}$}} & \multicolumn{3}{|c|}{ Yabancl ot yaş biyomast $\left(\mathrm{g} \mathrm{m}^{-2}\right)$} & \multicolumn{3}{|c|}{ Yabancl ot kuru biyomasl $\left(\mathrm{g} \mathrm{m}^{-2}\right)$} \\
\hline & & $2011 B$ & $2012 A$ & $\begin{array}{l}\text { Birleşik } \\
\text { analiz }\end{array}$ & $2011 B$ & $2012 \mathrm{~A}$ & $\begin{array}{l}\text { Birleşik } \\
\text { analiz }\end{array}$ \\
\hline $\begin{array}{l}\text { 1- Tohum ekim } \\
\text { glyphosate uyg }\end{array}$ & 0 gün önce & $44.36 \mathrm{c}$ & $764.60 \mathrm{a}$ & $404.48 \mathrm{ab}$ & $5.36 \mathrm{~d}$ & $126.49 \mathrm{~b}$ & $65.93 \mathrm{~b}$ \\
\hline $\begin{array}{l}\text { 2- Tohum ekim } \\
\text { glyphosate uyg }\end{array}$ & 11 gün & $137.92 \mathrm{a}$ & $637.68 \mathrm{~b}$ & $388.15 \mathrm{~b}$ & $19.61 \mathrm{a}$ & $117.01 \mathrm{bc}$ & $68.33 \mathrm{~b}$ \\
\hline $\begin{array}{l}\text { 3- Tohum ekim } \\
\text { glyphosate uyg }\end{array}$ & gün sonra & $62.76 \mathrm{~b}$ & $800.41 \mathrm{a}$ & $431.58 \mathrm{a}$ & $10.94 \mathrm{~b}$ & 258.84 a & $134.88 \mathrm{a}$ \\
\hline 4- Rotatiller ile & ik mücadele & $48.14 \mathrm{c}$ & $429.77 \mathrm{c}$ & $244.79 \mathrm{~d}$ & $9.52 \mathrm{c}$ & $71.39 \mathrm{~d}$ & $41.22 \mathrm{c}$ \\
\hline 5- Kontrol (çift & lamasi) & $16.72 \mathrm{~d}$ & $576.27 \mathrm{~b}$ & $296.49 \mathrm{c}$ & $2.26 \mathrm{e}$ & $95.61 \mathrm{c}$ & $48.94 \mathrm{c}$ \\
\hline \multicolumn{8}{|c|}{$\begin{array}{l}B \text {-Alt parsel } \\
\text { Herbisit ve mekanik uygulamalar }\end{array}$} \\
\hline $\begin{array}{l}\text { 1- Çıkış öncesi } \\
\text { uygulaması }\end{array}$ & sonras1 herbisit & $11.14 \mathrm{~d}$ & $387.91 \mathrm{c}$ & $199.52 \mathrm{c}$ & $3.46 \mathrm{c}$ & $63.06 \mathrm{c}$ & $33.25 \mathrm{c}$ \\
\hline $\begin{array}{l}\text { 2- Çıkış öncesi } \\
\text { çapalama }\end{array}$ & $t+$ frezeli & $30.40 \mathrm{c}$ & $893.04 \mathrm{~b}$ & $461.71 \mathrm{~b}$ & $3.96 \mathrm{c}$ & $156.73 \mathrm{~b}$ & $80.35 \mathrm{~b}$ \\
\hline $\begin{array}{l}\text { 3- Çık1ş sonras } \\
\text { çapalama }\end{array}$ & it + frezeli & $97.41 \mathrm{~b}$ & $273.20 \mathrm{c}$ & $185.30 \mathrm{c}$ & $15.99 \mathrm{a}$ & $42.77 \mathrm{c}$ & $29.38 \mathrm{c}$ \\
\hline $\begin{array}{l}\text { 4- Çıkış sonras } \\
\text { lister çapa) }\end{array}$ & (frezeli ve & $108.96 \mathrm{a}$ & $1012.84 \mathrm{a}$ & $565.85 \mathrm{a}$ & $14.74 \mathrm{~b}$ & $272.92 \mathrm{a}$ & $144.45 \mathrm{a}$ \\
\hline \multirow[t]{3}{*}{ Önem derecesi } & A & $* *$ & $* *$ & $* *$ & $* *$ & $* *$ & $* *$ \\
\hline & B & $* *$ & $* *$ & $* *$ & $* *$ & $* *$ & $* *$ \\
\hline & $\mathrm{AxB}$ & $* *$ & $* *$ & $* *$ & $* *$ & $* *$ & $* *$ \\
\hline VK & & 8.5 & 14.97 & 21 & 9.4 & 23.66 & 32.36 \\
\hline
\end{tabular}

**, $\mathrm{P}<0.001$; VK, varyasyon katsayısı; aynı sütunda aynı harfle gösterilen uygulamalar arasındaki fark önemli değildir

\section{Çizelge 4- Uygulamalardan sonra yabancı otların \% kaplama alanı}

Table 4- \% Weed coverage after applications

\begin{tabular}{|c|c|c|c|}
\hline & \multirow{2}{*}{ Uygulama } & \multicolumn{2}{|c|}{$\%$ Kaplama alanı } \\
\hline & & 2011 & 2012 \\
\hline \multirow{4}{*}{$\begin{array}{l}10 \text { gün önce glyphosate uy- } \\
\text { gulamas1 }\end{array}$} & Çıkış öncesi + çıkış sonrası herbisit & 15 & 20 \\
\hline & Ç1kış öncesi herbisit + frezeli çapa & 20 & 20 \\
\hline & Çıkış sonrası herbisit + frezeli çapa & 20 & 20 \\
\hline & Çıkış sonrası 2 çapa (frezeli + lister) & 40 (sıra üzeri) & 35 (sıra üzeri) \\
\hline \multirow{4}{*}{$\begin{array}{l}\text { Ekimle birlikte glyphosate } \\
\text { uygulaması }\end{array}$} & Çıkış öncesi + çıkış sonrası herbisit & 0 & 3 \\
\hline & Çıkış öncesi herbisit + frezeli çapa & 5 & 10 \\
\hline & Çıkış sonrası herbisit + frezeli çapa & 5 & 5 \\
\hline & Çıkış sonrası 2 çapa (frezeli + lister) & 40 (sıra üzeri) & 35 (sıra üzeri) \\
\hline \multirow{4}{*}{$\begin{array}{l}5 \text { gün sonra glyphosate } \\
\text { uygulamas1 }\end{array}$} & Çıkış öncesi + çıkış sonrası herbisit & 0 & 3 \\
\hline & Çıkış öncesi herbisit + frezeli çapa & 10 & 15 \\
\hline & Çıkış sonrası herbisit + frezeli çapa & 0 & 5 \\
\hline & Çıkış sonrası 2 çapa (frezeli + lister) & 40 (sıra üzeri) & 40 (sıra üzeri) \\
\hline \multirow[t]{4}{*}{ Mekanik uygulama } & Çıkış öncesi + çıkış sonrası herbisit & 0 & 5 \\
\hline & Çıkış öncesi herbisit + frezeli çapa & 40 & 25 \\
\hline & Ç1k1ş sonrası herbisit + frezeli çapa & 10 & 10 \\
\hline & Çıkış sonrası 2 çapa (frezeli + lister) & 60 (sıra üzeri) & 60 (sıra üzeri) \\
\hline \multirow[t]{4}{*}{ Kontrol (çiftçi uygulaması) } & Çıkış öncesi + çıkış sonrası herbisit & 0 & 5 \\
\hline & Ç1kış öncesi herbisit + frezeli çapa & 20 & 10 \\
\hline & Çıkış sonrası herbisit + frezeli çapa & 10 & 10 \\
\hline & Çıkış sonrası 2 çapa (frezeli + lister) & 60 (sıra üzeri) & 40 (sıra üzeri) \\
\hline
\end{tabular}


biyomas1 2011 yılında ekimle birlikte glyphosate uygulaması ve çıkış öncesi ve çıkış sonrası herbisit uygulaması yapılan parsellerden elde edilirken 2012 y1lında ise ekimden 10 gün önce ve 5 gün sonra glyphosate uygulaması ile çıkış öncesi ve çıkış sonras1 herbisit uygulamas1 yapilan parsellerden elde edilmiştir.

Toprak işlemeli şartlarda yabancı ot kuru biyomas değerleri $\left(\mathrm{g} \mathrm{m}^{-2}\right)$ interaksiyon değerleri yıllar bazında ve iki yılın birleştirilmiş analizi şeklinde Çizelge 6'da gösterilmiştir. İki yılı birlikte değerlendirildiğinde en yüksek yabanc1 ot kuru biyoması $378.8 \mathrm{~g} \mathrm{~m}^{-2}$ ekimden 5 gün sonra glyphosate uygulaması yapılan ana parsellere çıkış sonrası 2 çapa (frezeli+lister) uygulanan alt parsellerden elde edilirken, en düşük yabancı ot kuru biyoması ekimle birlikte glyphosate uygulaması yapılan ana parsellere çıkış öncesi ve çıkış sonrası herbisit uygulaması yapılan parsellerden elde edilmiştir (Çizelge 6).

Bu çalışma ile mısır yetiştiriciliğinde ekim öncesi ve çıkış öncesi total herbisit olan glyphosate'nin

\section{Çizelge 5- Yabancı ot yaş biyomas değerleri $\left(\mathrm{g} \mathrm{m}^{-2}\right)$ interaksiyon tablosu}

Table 5-Interaction table for weed fresh biomass values $\left(\mathrm{g} \mathrm{m}^{-2}\right)$

\begin{tabular}{|c|c|c|c|c|c|c|c|c|c|c|c|c|}
\hline \multirow{2}{*}{$\begin{array}{l}\text { Alt parsel } \\
\text { Ana parsel }\end{array}$} & \multicolumn{3}{|c|}{$\begin{array}{l}\text { Çıkış öncesi }+ \text { çıkış } \\
\text { sonrası herbisit }\end{array}$} & \multicolumn{3}{|c|}{$\begin{array}{c}\text { Çıkış öncesi herbisit } \\
+ \text { frezeli çapa }\end{array}$} & \multicolumn{3}{|c|}{$\begin{array}{c}\text { Çıkış sonrası herbisit } \\
+ \text { frezeli çapa }\end{array}$} & \multicolumn{3}{|c|}{$\begin{array}{l}\text { Çıkıs sonrası } 2 \text { çapa } \\
\text { (frezeli }+ \text { lister })\end{array}$} \\
\hline & 2011 & 2012 & $\begin{array}{l}\text { Birlessik } \\
\text { analiz* }\end{array}$ & 2011 & 2012 & $\begin{array}{c}\text { Birlessik } \\
\text { analiz }\end{array}$ & 2011 & 2012 & $\begin{array}{l}\text { Birlessik } \\
\text { analiz }\end{array}$ & 2011 & 2012 & $\begin{array}{l}\text { Birlessik } \\
\text { analiz }\end{array}$ \\
\hline $\begin{array}{l}10 \text { gün önce } \\
\text { glyphosate } \\
\text { uygulamas1 }\end{array}$ & $\begin{array}{c}4.1 \\
\mathrm{~m}\end{array}$ & $\begin{array}{l}18.8 \\
\operatorname{lm}\end{array}$ & $\begin{array}{c}11.5 \\
\mathrm{k}\end{array}$ & $\begin{array}{c}56.3 \\
\operatorname{lm}\end{array}$ & $\begin{array}{c}1082.6 \\
\text { de }\end{array}$ & $\begin{array}{l}569.5 \\
\text { cd }\end{array}$ & $\begin{array}{c}11.8 \\
\mathrm{~m}\end{array}$ & $\begin{array}{c}1018.5 \\
\text { ef }\end{array}$ & $\begin{array}{c}515.1 \\
\mathrm{de}\end{array}$ & $\begin{array}{c}105.1 \\
\mathrm{kl}\end{array}$ & $\begin{array}{c}938.3 \\
\mathrm{f}\end{array}$ & $\begin{array}{l}521.7 \\
\text { ce }\end{array}$ \\
\hline $\begin{array}{l}\text { Ekimle birlikte } \\
\text { glyphosate } \\
\text { uygulamas1 }\end{array}$ & $\begin{array}{c}0 \\
\mathrm{~m}\end{array}$ & $\begin{array}{l}84.3 \\
\mathrm{~km}\end{array}$ & $\begin{array}{c}42.1 \\
\mathrm{k}\end{array}$ & $\begin{array}{l}14.3 \\
\operatorname{lm}\end{array}$ & $\begin{array}{c}966.7 \\
\mathrm{f}\end{array}$ & $\begin{array}{c}490.5 \\
\mathrm{e}\end{array}$ & $\underset{\mathrm{ij}}{249.8}$ & $\begin{array}{l}88.0 \\
\mathrm{~km}\end{array}$ & $\begin{array}{c}168.9 \\
\mathrm{hi}\end{array}$ & $\begin{array}{c}290.3 \\
i\end{array}$ & $\begin{array}{c}1411.6 \\
b\end{array}$ & $\begin{array}{l}850.9 \\
\mathrm{a}\end{array}$ \\
\hline $\begin{array}{l}5 \text { gün sonra } \\
\text { Glyphosate } \\
\text { uygulamas1 }\end{array}$ & $\begin{array}{l}31.0 \\
1 \mathrm{~m}\end{array}$ & $\begin{array}{l}40.8 \\
\operatorname{lm}\end{array}$ & $\begin{array}{c}35.9 \\
\mathrm{k}\end{array}$ & $\begin{array}{l}77.6 \\
\mathrm{~km}\end{array}$ & $\begin{array}{c}1284.3 \\
c\end{array}$ & $\begin{array}{c}681.0 \\
b\end{array}$ & $\begin{array}{l}36.9 \\
1 \mathrm{~m}\end{array}$ & $\begin{array}{l}239.7 \\
\mathrm{ij}\end{array}$ & $\begin{array}{c}138.4 \\
\mathrm{ij}\end{array}$ & $\begin{array}{c}105.3 \\
\mathrm{kl}\end{array}$ & $\begin{array}{c}1636.7 \\
\mathrm{a}\end{array}$ & $\begin{array}{c}871.0 \\
\mathrm{a}\end{array}$ \\
\hline $\begin{array}{l}\text { Mekanik } \\
\text { uygulama }\end{array}$ & $\begin{array}{c}20.4 \\
\operatorname{lm}\end{array}$ & $\begin{array}{l}612.6 \\
\mathrm{~g}\end{array}$ & $\begin{array}{c}316.5 \\
\mathrm{f}\end{array}$ & $\begin{array}{c}0 \\
\mathrm{~m}\end{array}$ & $\begin{array}{c}478.2 \\
\mathrm{~h}\end{array}$ & $\begin{array}{l}239.0 \\
\text { gh }\end{array}$ & $\begin{array}{c}162.9 \\
\mathrm{jk}\end{array}$ & $\begin{array}{c}0.9 \\
\mathrm{~m}\end{array}$ & $\begin{array}{l}81.9 \\
\mathrm{jk}\end{array}$ & $\begin{array}{l}55.8 \\
\operatorname{lm}\end{array}$ & $\begin{array}{c}627.3 \\
\mathrm{~g}\end{array}$ & $\begin{array}{c}341.5 \\
\mathrm{f}\end{array}$ \\
\hline $\begin{array}{l}\text { Kontrol (Çiftçi } \\
\text { uygulaması) }\end{array}$ & $\begin{array}{l}0 \\
\mathrm{~m}\end{array}$ & $\begin{array}{l}1182.8 \\
\mathrm{~cd}\end{array}$ & $\begin{array}{l}591.4 \\
\mathrm{c}\end{array}$ & $\begin{array}{c}3.5 \\
\mathrm{~m}\end{array}$ & $\begin{array}{c}653.3 \\
\mathrm{~g}\end{array}$ & $\begin{array}{c}328.4 \\
\mathrm{f}\end{array}$ & $\begin{array}{l}25.4 \\
\operatorname{lm}\end{array}$ & $\begin{array}{l}18.7 \\
\mathrm{~lm}\end{array}$ & $\begin{array}{c}22.1 \\
\mathrm{k}\end{array}$ & $\begin{array}{c}37.7 \\
\mathrm{~lm}\end{array}$ & $\begin{array}{c}450.1 \\
\mathrm{~h}\end{array}$ & $\begin{array}{c}243.9 \\
\mathrm{~g}\end{array}$ \\
\hline
\end{tabular}

*, Birleşik analiz ayrıca gruplandırılmıştır; **, aynı harfle gösterilen uygulamalar arasında $L S D$ testine göre $(P<0.05)$ fark yoktur

\section{Çizelge 6- Yabancı ot kuru biyomas değerleri $\left(\mathrm{g} \mathrm{m}^{-2}\right)$ interaksiyon tablosu}

Table 6- Interaction table for weed dry biomass values $\left(\mathrm{g} \mathrm{m}^{-2}\right)$

\begin{tabular}{|c|c|c|c|c|c|c|c|c|c|c|c|c|}
\hline \multirow[b]{2}{*}{ Ana parsel } & \multicolumn{3}{|c|}{$\begin{array}{l}\text { Çıkış öncesi }+ \text { çıkış } \\
\text { sonrası herbisit }\end{array}$} & \multicolumn{3}{|c|}{$\begin{array}{l}\text { Çıkış öncesi herbisit } \\
\quad+\text { frezeli çapa }\end{array}$} & \multicolumn{3}{|c|}{$\begin{array}{l}\text { Çıkış sonrası herbisit } \\
\quad+\text { frezeli çapa }\end{array}$} & \multicolumn{3}{|c|}{$\begin{array}{l}\text { Çıkış sonrası } 2 \text { çapa } \\
\text { (frezeli }+ \text { lister) }\end{array}$} \\
\hline & 2011 & 2012 & $\begin{array}{l}\text { Birlessik } \\
\text { analiz* }\end{array}$ & 2011 & 2012 & $\begin{array}{c}\text { Birleşik } \\
\text { analiz }\end{array}$ & 2011 & 2012 & $\begin{array}{c}\text { Birleşik } \\
\text { analiz }\end{array}$ & 2011 & 2012 & $\begin{array}{c}\text { Birleşik } \\
\text { analiz }\end{array}$ \\
\hline $\begin{array}{l}10 \text { gün önce } \\
\text { glyphosate } \\
\text { uygulamas1 }\end{array}$ & 0.8 & $\begin{array}{l}3.0 \\
\mathrm{ij}\end{array}$ & $\begin{array}{c}1.9 \\
\mathrm{k}\end{array}$ & $\begin{array}{l}7.2 \\
\mathrm{hj}\end{array}$ & $\begin{array}{c}176.4 \\
\mathrm{~cd}\end{array}$ & $\begin{array}{c}91.8 \\
\mathrm{~cd}\end{array}$ & $\begin{array}{l}1.7 \\
\mathrm{j}\end{array}$ & $\begin{array}{c}148.7 \\
\mathrm{~d}\end{array}$ & $\begin{array}{c}75.2 \\
\text { de }\end{array}$ & $\begin{array}{c}11.6 \\
\mathrm{gj}\end{array}$ & $\begin{array}{c}177.7 \\
\mathrm{~cd}\end{array}$ & $\begin{array}{l}94.6 \\
\mathrm{~cd}\end{array}$ \\
\hline $\begin{array}{l}\text { Ekimle birlikte } \\
\text { glyphosate } \\
\text { uygulamas1 }\end{array}$ & $\begin{array}{l}0 \\
\mathrm{j}\end{array}$ & $\begin{array}{l}8.8 \\
\text { gj }\end{array}$ & $\begin{array}{l}4.4 \\
\mathrm{jk}\end{array}$ & $\frac{1.5}{j}$ & $\begin{array}{c}192.1 \\
\mathrm{c}\end{array}$ & $\begin{array}{c}96.8 \\
\mathrm{~cd}\end{array}$ & $\begin{array}{l}38.5 \\
\text { fg }\end{array}$ & $\begin{array}{c}16.4 \\
\mathrm{fj}\end{array}$ & $\begin{array}{c}27.5 \\
\text { gi }\end{array}$ & $\begin{array}{l}38.3 \\
\text { fh }\end{array}$ & $\begin{array}{c}250.7 \\
b\end{array}$ & $\begin{array}{c}144.5 \\
\mathrm{~b}\end{array}$ \\
\hline $\begin{array}{l}5 \text { gün sonra } \\
\text { Glyphosate } \\
\text { uygulaması }\end{array}$ & $\begin{array}{c}14.1 \\
\mathrm{gj}\end{array}$ & $\begin{array}{l}6.4 \\
\mathrm{hj}\end{array}$ & $\begin{array}{l}10.2 \\
\mathrm{ik}\end{array}$ & $\begin{array}{l}10.0 \\
\mathrm{gj}\end{array}$ & $\begin{array}{c}242.4 \\
b\end{array}$ & $\begin{array}{c}126.2 \\
b\end{array}$ & 3.3 & $\begin{array}{l}45.07 \\
\mathrm{f}\end{array}$ & $\begin{array}{c}24.2 \\
\mathrm{hj}\end{array}$ & $\begin{array}{c}16.2 \\
\mathrm{fj}\end{array}$ & $\begin{array}{c}741.3 \\
\mathrm{a}\end{array}$ & $\begin{array}{c}378.8 \\
\quad \mathrm{a}\end{array}$ \\
\hline $\begin{array}{l}\text { Mekanik } \\
\text { uygulama }\end{array}$ & 2.3 & $\begin{array}{l}99.8 \\
\mathrm{e}\end{array}$ & $\underset{f}{51.1}$ & $\begin{array}{l}0 \\
j\end{array}$ & $\begin{array}{c}81.1 \\
\mathrm{e}\end{array}$ & $\begin{array}{l}40.5 \\
\text { fh }\end{array}$ & $\begin{array}{c}33.2 \\
\text { fi }\end{array}$ & $\begin{array}{c}0.1 \\
\mathrm{j}\end{array}$ & $\begin{array}{l}16.6 \\
\mathrm{ik}\end{array}$ & $\begin{array}{l}8.5 \\
\mathrm{hj}\end{array}$ & $\begin{array}{c}104.4 \\
\mathrm{e}\end{array}$ & $\begin{array}{l}56.5 \\
\text { ef }\end{array}$ \\
\hline $\begin{array}{l}\text { Kontrol (Çiftçi } \\
\text { uygulaması) }\end{array}$ & $\begin{array}{l}0 \\
\mathrm{j}\end{array}$ & $\begin{array}{c}197.1 \\
\mathrm{c}\end{array}$ & $\begin{array}{c}98.5 \\
\mathrm{c}\end{array}$ & $\begin{array}{c}0.9 \\
\mathrm{j}\end{array}$ & $\begin{array}{c}91.5 \\
\mathrm{e}\end{array}$ & $\begin{array}{c}46.2 \\
\mathrm{fg}\end{array}$ & $\begin{array}{c}3.12 \\
\mathrm{ij}\end{array}$ & $\begin{array}{c}3.4 \\
\mathrm{ij}\end{array}$ & $\begin{array}{l}3.3 \\
\mathrm{jk}\end{array}$ & $\begin{array}{c}5.0 \\
\mathrm{ij}\end{array}$ & $\begin{array}{c}90.3 \\
\mathrm{e} \\
\end{array}$ & $\begin{array}{c}47.6 \\
\mathrm{fg}\end{array}$ \\
\hline
\end{tabular}

*, Birleşik analiz ayrıca gruplandırılmıştır; **, aynı harfle gösterilen uygulamalar arasında $L S D$ testine göre $(P<0.05)$ fark yoktur. 
kullanılabileceği ortaya konmuştur. Misır bitkisi çıkmadan önce kullanilan glyphosate misirda fitotoksiteye neden olmamaktadır. Bu sonuçlar Ülkemizde pamukta Doğan et al (2009) tarafindan yapılan çalışma ile paraleldir.

Yürütülen bu çalışmada, erken toprak işlemesi çiftçi uygulaması ile karşılaştırıldığında yabancı otların biyomaslarında ve kaplama alanlarında herhangi bir azalma meydana getirmemiştir. Çimlenme bölgesinden yabancı otların çıkış yapmas1; yabanc1 ot türüne, toprak tipine, toprak işlemeye ve toprağın fiziksel özelliklerine göre değişmektedir (Buhler \& Mester 1991; Mohler \& Galford 1997). Deneme yapılan alandaki tohum bankasının zenginliği ve deneme kurulduğu dönem olan Mayıs ayındaki sürekli yağışların yeniden yabancı ot çıkışını teşvik etmesinin farklılık çıkmasını engellediği düşülmektedir. Bununla birlikte çiftçilerimizin uzun dönemde erken toprak işlemesi yapmalarının menfaatlerine olacağı düşünülmektedir. Bununla birlikte erken toprak işlemenin popülerlik kazandığ 1 ve bu sistemin soya, mısır, pamuk ve çeltikte kullanımının adapte edildiği ileri sürülmüş (Shaw 1996) ancak bu sistemin kısmı başarı sağladığını dolayısı ile tek başına değil diğer yabanc1 ot mücadele yöntemlerine entegre edilmesi gerektiği bildirilmiştir (Caldwell \& Mohler 2001).

\subsection{Uygulamalarin misir verimi ve verim unsurlarina etkisi}

Yabancı ot mücadele uygulamalarının misır verim ve verim unsurları ile ilgili incelenen karakterlere istatistiki analiz uygulanmış olup sonuçlar yıllar bazında Çizelge 7'de gösterilmiştir. Her iki yılda da incelenen karakterler açısından istatistiki olarak farklılık çıkmadığı için birleştirilmiş analiz yapılmamıştır. Çizelge 7 incelendiğinde, mısırın nem, tane/koçan oranı ve dekara verim değerleri, gerek ana parsel konularından ve gerekse alt parsel konularından önemli derecede etkilenmediği görülmektedir. Bununla birlikte en fazla nem değeri \% 29.5 ile 2012 y1lında rotatiller ile mekanik

\section{Çizelge 7- Uygulamaların mısır verim ve verim unsurlarına etkisi}

Table 7- The effect of treatments on corn yield and yield components

\begin{tabular}{|c|c|c|c|c|c|c|c|}
\hline \multirow{2}{*}{\multicolumn{2}{|c|}{$\begin{array}{l}\text { A-Ana parseller- } \\
\text { Glyposate uygulama zamanlarl }\end{array}$}} & \multicolumn{2}{|c|}{$\begin{array}{l}\mathrm{Nem} \\
(\%)\end{array}$} & \multicolumn{2}{|c|}{$\begin{array}{c}\text { Tane / koçan } \\
\text { oranı (\%) }\end{array}$} & \multicolumn{2}{|c|}{$\begin{array}{c}\text { Verim } \\
\left(k g d a^{-1}\right)\end{array}$} \\
\hline & & 2011 & 2012 & 2011 & 2012 & 2011 & 2012 \\
\hline 1- Tohum ekim & gün önce glifosate uygulaması & 26 & 26.9 & 76 & 77.75 & 584 & 689.5 \\
\hline $\begin{array}{l}\text { 2- Tohum ekim } \\
\text { uygulamas1 }\end{array}$ & gün glifosate & 26 & 27.6 & 76 & 77.91 & 598 & 683.6 \\
\hline $\begin{array}{l}\text { 3- Tohum ekim } \\
\text { uygulamas1 }\end{array}$ & gün sonra glifosate & 26 & 28.2 & 76 & 77.41 & 615 & 676.3 \\
\hline 4- Rotatiller ile & K mücadele & 26 & 29.5 & 76 & 77.83 & 618 & 671.4 \\
\hline 5- Kontrol (çift & amas1) & 27 & 28.4 & 76 & 78.58 & 641 & 700.4 \\
\hline \multicolumn{8}{|c|}{ B-Alt konular-herbisit ve mekanik uygulamalar } \\
\hline $\begin{array}{l}\text { 1.Çıkış öncesi } \\
\text { uygulaması }\end{array}$ & nnrası herbisit & 26 & 28 & 76 & 78.26 & 606 & 687.9 \\
\hline 2. Ç1k1ş öncesi & + frezeli çapalama & 26 & 28 & 76 & 78.13 & 619 & 692 \\
\hline 3. Ç1k1ş sonras & + frezeli çapalama & 26 & 28.1 & 76 & 78.00 & 617 & 686.6 \\
\hline 4. Ç1k1ş sonras & frezeli ve lister çapa) & 26 & 28.4 & 76 & 78.58 & 604 & 670.5 \\
\hline \multirow[t]{3}{*}{ Önem derecesi } & A & öd & öd & öd & öd & öd & öd \\
\hline & $\mathrm{B}$ & öd & öd & öd & öd & öd & öd \\
\hline & $\mathrm{AxB}$ & öd & $*$ & öd & $*$ & öd & öd \\
\hline VK & & 8.22 & 4.09 & 2.23 & 1.64 & 11.45 & 4.78 \\
\hline
\end{tabular}

Tarım Bilimleri Dergisi - Journal of Agricultural Sciences 21 (2015) 596-605 
mücadele yapılan parsellerde saptanmıştır. Genel anlamda 2012 yılındaki dane misırın nemi 2011 yılından az da olsa yüksek çıkmıştır. Uygulamaların her iki yılda da verim üzerine etkileri istatistiki açıdan önemli çıkmasa da 2012 yılı verileri 2011 'den yüksek çıkmıştır. Ana parsel konuları olan glyphosate uygulama zamanları incelendiğinde, glyphosate'nin erken ya da geç uygulamasının ve mekanik mücadele ile çiftçi uygulamaları arasında verim değerleri bakımından fark görülmemiştir. Elde edilen sonuçlar sürekli mısır yetiştiriciliği yapılan sistemde, ürün yabancı otsuz tutulduğunda toprak işleme sistemlerinin verimi etkilemediği, ancak yabanc1 ot mücadelesindeki farklılıkların verimde farklılıklara yol açabildiği (Buhler 1992; Duiker et al 2006) görüşü ile uyumludur. Alt parsellere yapılan uygulamalar yabancı ot rekabetini engellemiş ve istatistiki olarak verimler arasında farklılık çıkmamıştır.

\subsection{Uygulamaların ekonomik analizi}

Uygulamalar arasında mali açıdan farklılıkların belirlenmesi amacıyla ekonomik analiz yapılmıştır (Çizelge 8). Çalışmada bütün glyphosate uygulamalarında yapılan masraf aynı olup değişen tek faktör uygulama zamanı olmuştur. Bu nedenle ekonomik analiz yapılırken glyphosate uygulama zamanları ayrı ayrı dikkate alınmamıştır. Ekim öncesi total herbisit uygulamaları dekar başına net gelirde azalmalara sebebiyet vermiş̧ir. Gerek total herbisitin uygulandığ 1 gerekse de uygulanmadığ1 alanlarda en yüksek net gelir çıkış öncesi ve çıkış sonrası herbisit uygulamalarının yapıldığı alanlardan elde edilmiştir. Yapılan çapa uygulamalarının maliyeti artırdığı için net geliri de azalttığı tespit edilmiştir.

\section{Sonuçlar}

$\mathrm{Bu}$ çalışma ile mısır üretim alanlarındaki yabancı ot yoğunluğunu azaltmak amaciyla total bir herbisit olan glyphosate'nin ekim öncesi ve çıkış öncesi kullanılabileceği ancak bu uygulamanın maliyeti artırdığı saptanmıştır. Kritik periyot döneminde misir1 yabanc1 ot rekabetinden korumak amaciyla en etkin ve en uygun sonuca çıkış öncesi ve çıkış sonrası herbisit uygulaması ile ulaşılabileceği, mekanik mücadele yöntemlerinin ise maliyeti artırmasindan dolayı net gelirde azalmalara sebebiyet verdiği belirlenmiştir. Yabanc1 ot mücadelesinde erken toprak işleme entegre mücadele içerisinde diğer yöntemlerle birlikte kullanılmalıdır.

\section{Teşekkür}

Bu çalışma Tarımsal Araştırmalar ve Politikalar Genel Müdürlüğü tarafindan TAGEM-BS-10/07-03/04-01 nolu proje kapsamında desteklenmiştir. Katkılarından

\section{Çizelge 8- Uygulamaların dane mısır üretimine etkilerinin ekonomik analizi (TL da $\mathbf{~ d a}^{-1}$ )}

Table 8-Economic analyses of the effects of treatments on kernel corn production (TL da ${ }^{-1}$ )

\begin{tabular}{|c|c|c|c|c|c|c|c|c|}
\hline \multirow[b]{4}{*}{ Iş̧lem sırası } & \multicolumn{4}{|c|}{ Glyphosate uygulanan } & \multicolumn{4}{|c|}{ Glyphosate uygulanmayan } \\
\hline & \multirow{3}{*}{$\begin{array}{c}\text { Ç.Ö+Ç.S } \\
\text { Herb } \\
\left(T L d a^{-1}\right)\end{array}$} & \multirow{3}{*}{$\begin{array}{l}C ̧ . \ddot{O}+\text { çapa } \\
\left(T L d a^{-1}\right)\end{array}$} & \multirow{3}{*}{$\begin{array}{l}\text { Ç.S + çapa } \\
\left(T L d a^{-1}\right)\end{array}$} & \multirow{3}{*}{$\begin{array}{l}2 \text { çapa } \\
\left(T L d a^{-1}\right)\end{array}$} & \multirow{3}{*}{$\begin{array}{c}C \zeta . \ddot{O}+C ̧ . S \\
\text { Herb } \\
\left(T L d a^{-1}\right)\end{array}$} & \multirow{3}{*}{$\begin{array}{l}C ̧ . \ddot{O}+\text { çapa } \\
\left(T L d a^{-1}\right)\end{array}$} & \multirow{3}{*}{$\begin{array}{l}C ̧ . S+\text { çapa } \\
\left(T L d a^{-1}\right)\end{array}$} & \multirow{3}{*}{$\begin{array}{c}2 \text { çapa } \\
\left(T L d a^{-1}\right)\end{array}$} \\
\hline & & & & & & & & \\
\hline & & & & & & & & \\
\hline Toplam üretim masrafları & 414.43 & 412.43 & 419.43 & 412.43 & 399.23 & 397.23 & 404.23 & 402.23 \\
\hline $\operatorname{Verim}\left(\mathrm{kg} \mathrm{da}^{-1}\right)$ & 706.60 & 698.13 & 712.16 & 684.30 & 718.80 & 703.30 & 710.86 & 668.53 \\
\hline Satış fiyatı (TL kg-1) & 0.60 & 0.60 & 0.60 & 0.60 & 0.60 & 0.60 & 0.60 & 0.60 \\
\hline Ana ürün geliri ( $\left.\mathrm{TL} \mathrm{da}^{-1}\right)$ & 423.96 & 418.88 & 427.30 & 410.58 & 431.28 & 421.98 & 426.52 & 401.12 \\
\hline Yan ürün geliri $\left(\mathrm{TL} \mathrm{da}^{-1}\right)$ & 60.00 & 60.00 & 60.00 & 60.00 & 60.00 & 60.00 & 60.00 & 60.00 \\
\hline Gayri safi üretim değeri $\left(\mathrm{TL} \mathrm{da}^{-1}\right)$ & 483.96 & 478.88 & 487.30 & 470.58 & 491.28 & 481.98 & 486.52 & 461.12 \\
\hline Net gelir $\left(\mathrm{TL} \mathrm{da}{ }^{-1}\right)$ & 69.53 & 66.45 & 67.87 & 58.15 & 92.05 & 84.75 & 82.29 & 58.89 \\
\hline
\end{tabular}

Ç.Ö, çıkış öncesi herbisit; Ç.S, çıkış sonrası herbisit 
dolayı TAGEM'e ve Karadeniz Tarımsal Araştırma Enstitüsü Müdürlüğüne teşekkür ederiz

\section{Kaynaklar}

Buhler D D \& Mester T C (1991). Effect of tillage systems on the emergence depth of giant (Setaria faberi) and green foxtail (Setearia viridis). Weed Science 39: 200-203

Buhler D D (1992). Population dynamics and control of annual weeds in corn (Zea mays) as influenced by tillage systems. Weed Science 40: 241-248

Caldwell B \& Mohler C L (2001). Stale seedbed practices for vegetable production. Horticulture Science 36: 703-705

Cousens R \& Moss S R (1990). A model of the effects of cultivation on the vertical distribution of weed seeds within the soil. Weed Research 30: 61-70

Doğan M N, Unay A, Boz O \& Oğüt D (2009). Effect of pre-sowing and pre-emergence glyphosate applications on weeds in stale seedbed cotton Crop Protection 28: 503-507

Duiker S W, Haldemann J F Jr \& Johnson D H (2006). Tillage $\mathrm{x}$ maize hybrid interactions. Agronomy Journal 98: 436-442
Işı1k D, Mennan H, Bukun B, Oz A \& Ngouajio M (2006). The critical period for weed control in corn in Turkey. Weed Techlonogy 20(4): 867-872

Kır K \& Doğan M N (2009). Weed control in maize (Zea mays L.) with effective minimum rates of foramsulfuron. Turkish Journal of Agriculture and Forestry 33: 601-610

Mohler C L \& Galford A E (1997). Weed seedling emergence and seed survival: separating the effects of seed position and soil modification by tillage. Weed Research 37: 147-155

Oerke E C \& Dehne H W (2004). Safequarding production-losses in major crops and the role of crop protection. Crop Protection 23: 275-285

Özata E \& Kapar H (2013). Bazı atdişi hibrit mısır (Zea mays indentata Sturt) genotiplerinin samsun koşullarında kalite ve performanslarının belirlenmesi. Tartm Bilimleri Araştırma Dergisi 6(2): 19-2

Özer Z (1993). Niçin Yabancı Ot Bilimi Türkiye I. Herboloji Kong. Bildirileri. 1-7 s. Adana

SPSS (2012). Statistical package for statistical science. IBM ${ }^{\circledR S P S S}{ }^{\circledR}$ Version 20.(http//:spss.int.omu.edu.tr)

Shaw D R (1996). Development of stale seedbed weed control programs for Southern row crops. Weed Science 44(2): 413-416 